\title{
Evaluation of the antimicrobial activity and cytotoxicity of phytogenic gold nanoparticles
}

\author{
T. V. M. Sreekanth $\cdot$ P. C. Nagajyothi • \\ N. Supraja • T. N. V. K. V. Prasad
}

Received: 31 July 2014/Accepted: 25 August 2014/Published online: 7 September 2014

(C) The Author(s) 2014. This article is published with open access at Springerlink.com

\begin{abstract}
Among the nanoscale materials, noble metal nanoparticles have been attracting the scientific community due to their unique properties and selectivity in biological applications. In the present investigation, gold nanoparticles (AuNPs) were synthesized using rhizome extract of Dioscorea batatas through a simple, clean, inexpensive and eco-friendly method. Treating $1 \mathrm{mM}$ chloroauric acid $\left(\mathrm{HAuCl}_{4}\right)$ with the rhizome extract at $50{ }^{\circ} \mathrm{C}$ resulted in the formation of AuNPs. The reduction of AuNPs was observed by the color change of the solution from colorless to dark red wine. The synthesized nanoparticles were characterized using the techniques UV-Vis spectrophotometers, Fourier transform infrared spectroscopy, X-ray diffraction, scanning electron microscopy and transmission electron microscopy. Green synthesized AuNPs were found to be toxic against gram-positive and gram-negative bacteria in liquid media. MTT (dimethyl thiazolyl diphenyl tetrazolium salt) assay showed $21.5 \%$ cell inhibition in lower concentration $(0.2 \mathrm{mM})$ and $>50 \%$ cell inhibition after $48 \mathrm{~h}$ exposure at higher concentrations $(0.8-1 \mathrm{mM})$.
\end{abstract}

T. V. M. Sreekanth

Department of Life Chemistry, Catholic University of Daegu,

Hayang-eup, Gyeongsan-si, Geyongbuk 712-702,

Republic of Korea

P. C. Nagajyothi

Department of Nanomaterials Chemistry, Dongguk University, Seokjang-dong 707, Gyeongju 780 714, Republic of Korea

N. Supraja · T. N. V. K. V. Prasad ( $₫)$

Regional Agricultural Research Station, Nanotechnology

Laboratory, Institute of Frontier Technology, Acharya N G

Ranga Agricultural University, Tirupati, AP 517 502, India

e-mail: tnvkvprasad@gmail.com
Keywords Green synthesis - Dioscorea batatas . Antibacterial studies · Cytotoxicity · AuNPs

\section{Introduction}

Nanotechnology is a term regularly used in recent years to describe a set of technologies that deal with objects whose measured size is in the range of $1-100 \mathrm{~nm}$ in at least one dimension (Prasad and Giridhara Krishna 2012). The gold nanoparticles can be synthesized using the top-down (physical methods such as thermal decomposition, diffusion, irradiation, etc.) and bottom-up (chemical polyol synthesis method, electrochemical synthesis, chemical reduction), and biological entities for fabrication of nanoparticles (Tikariha et al. 2012). The most popular chemical synthetic methods that are used to prepare nanoparticles require high pressure, high temperature and toxic chemicals like, sodium borohydrate, citrate and alcohols as reducing and capping agents. These agents may have associated environmental pollution because of the toxic organic solvent and external reducing agent used that will affect the environment (Sharma et al. 2009; Bar et al. 2009). Gold nanoparticles (AuNPs) have received major attention by the scientific community as well as industry because of their unique physical and chemical properties. It has been reported that there are a number of potential avenues in which AuNPs were applied including photonics, electronics (Ramgopal et al. 2011), chromatographic techniques (Mayer et al. 2011), Catalysis (Li-Na et al. 2011), identification of pathogens in clinical specimens (Singaravelu et al. 2007), biosensing, gene therapy and DNA sequencing (Thirumurugan et al. 2010). Use of plant extract, fungi, yeast, bacteria and algae could be an alternative to chemical and physical methods for the production

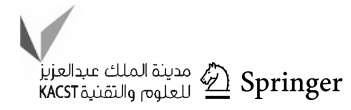




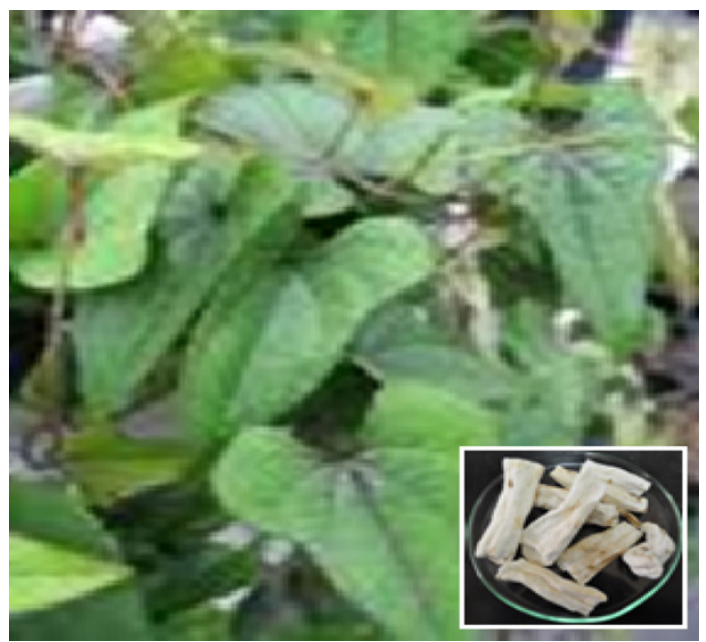

Fig. 1 Typical picture showing the plant Dioscorea batatas and rhizome (inset)

of nanoparticles in an eco-friendly manner. Several plants such as Momordica charantia (Sunil et al. 2012), Memecylon umbellatum (Arunachalam et al. 2013), Mangifera indica (Phillip 2010), Trigonella foenum-graecum (Aswathy Aromal and Philip 2012), Carthamus tinctorius (Nagajyothi et al. 2012), Teraxacum officinale (Tetty et al. 2012), Citrus reticulate (Nagajyothi et al. 2013) and Lonicera Japonica (Nagajyothi et al. 2012) have been successfully used for efficient and rapid extracellular synthesis of gold nanoparticles. Dioscorea grows extensively on mountains as well as in fields within Korea and Japan. The rhizomes of Dioscorea batatas are traditionally used to treat coronary artery disorder caused by blood clotting ( $\mathrm{Au}$ et al. 2004), and to improve immunity (Phillip 2010; Choi and Hwang 2002). It is also reported the antioxidative reactivity (Choi et al. 2003) and its ability to decrease blood glucose levels (Morrison et al. 2006). In this paper, we present a simple and rapid biosynthesis of gold nanoparticles using Dioscorea batatas extract. As prepared, gold nanoparticles were characterized by various methods, such as UV-Vis spectroscopy, FT-IR, SEM-EDS, TEM and XRD. This work provided a potential approach for the production of gold nanoparticles without the involvement of additional chemicals and physical steps.

\section{Materials and methods}

Biosynthesis of gold nanoparticles

Dioscorea rhizomes were collected from Gyeongju Oriental Medical College, Gyeongju, South Korea (Fig. 1). The rhizomes were air-dried for 10 days, then kept in a hot air oven at $60{ }^{\circ} \mathrm{C}$ for $24 \mathrm{~h}$. Rhizomes were ground to fine powder. $5 \mathrm{~g}$ of powder was mixed in $100 \mathrm{ml}$ of water and
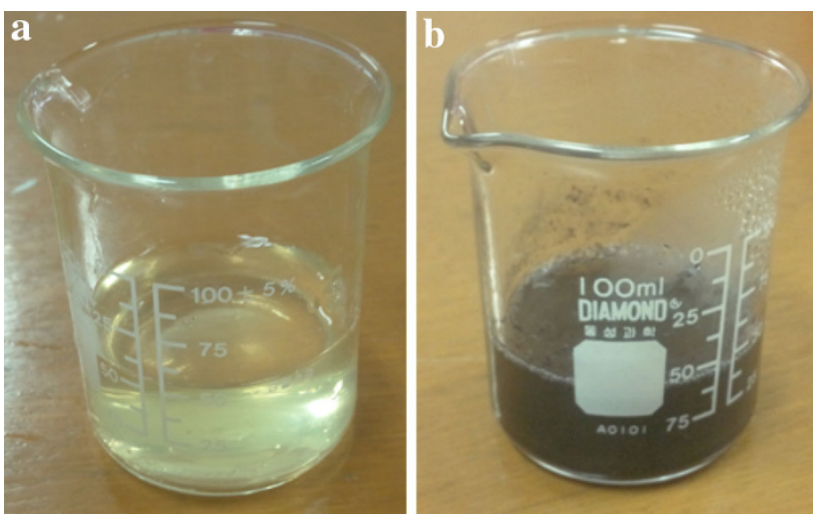

Fig. 2 Color changing of rhizome extracts containing a before synthesis of gold nanoparticles and $\mathbf{b}$ after synthesis of gold nanoparticles at $50{ }^{\circ} \mathrm{C}$

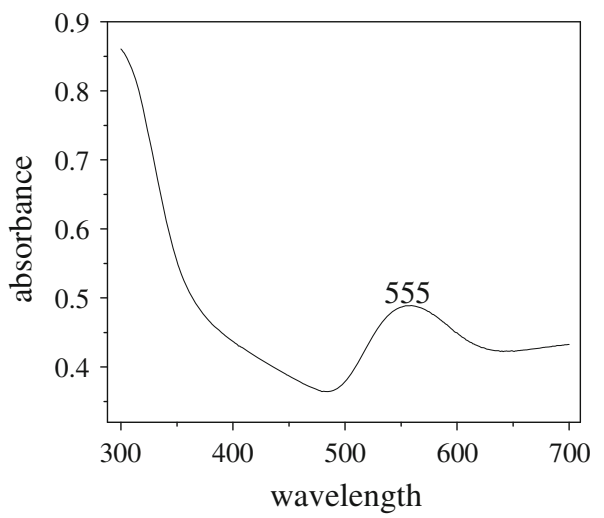

Fig. 3 UV-Vis absorption spectrum showing the localized surface plasma resonance at $555 \mathrm{~nm}$ of AuNPs synthesized using the rhizome extract of Dioscorea batatas

boiled at $100{ }^{\circ} \mathrm{C}$ for $10 \mathrm{~min}$ and the solution was filtered using Whatman filter paper (No. 41) and the extract was collected and stored in a plastic bottle. $190 \mathrm{ml}$ of $1 \mathrm{mM}$ chloro auric acid $\left(\mathrm{HAuCl}_{4}\right.$ purchased from Sigma-Aldrich Chemical Pvt. Ltd.) was added to $10 \mathrm{ml}$ of rhizome extract to make up a final solution $200 \mathrm{ml}(10 \mathrm{ml}$ rhizome extract $+190 \mathrm{ml} \mathrm{HAuCl}_{4}$ solution). A change in the color of solution was observed during the heating process at $50{ }^{\circ} \mathrm{C}$.

\section{Characterization of AuNPs}

The Localized Surface Plasmon Resonance (LSPR) of AuNPs was recorded using UV-visible spectrophotometer (Cary $4000 \mathrm{UV}-\mathrm{Vis}$ spectrophotometer) with the scanning range $200-800 \mathrm{~nm}$. Air-dried, platinum coated samples were performed using an analytical scanning electron microscope (Hitachi s-3500N) equipped with an energy dispersive X-ray spectrum (EDS), TEM (H-7100 Hitachi), XRD Philips (Netherlands) and FT-IR (Bruker model, 
Fig. 4 Energy dispersion X-ray spectrum (EDS) micrograph of bio-synthesized AuNPs showing the elemental presence of $\mathrm{Au}, \mathrm{C}$ and $\mathrm{K}$

Fig. 5 Transmission electron microscopic micrograph (200 nm bar) showing polydispersed gold nanoparticles (size $18.48-56.18 \mathrm{~nm}$ ) synthesized using the extract of Dioscorea batatas rhizome
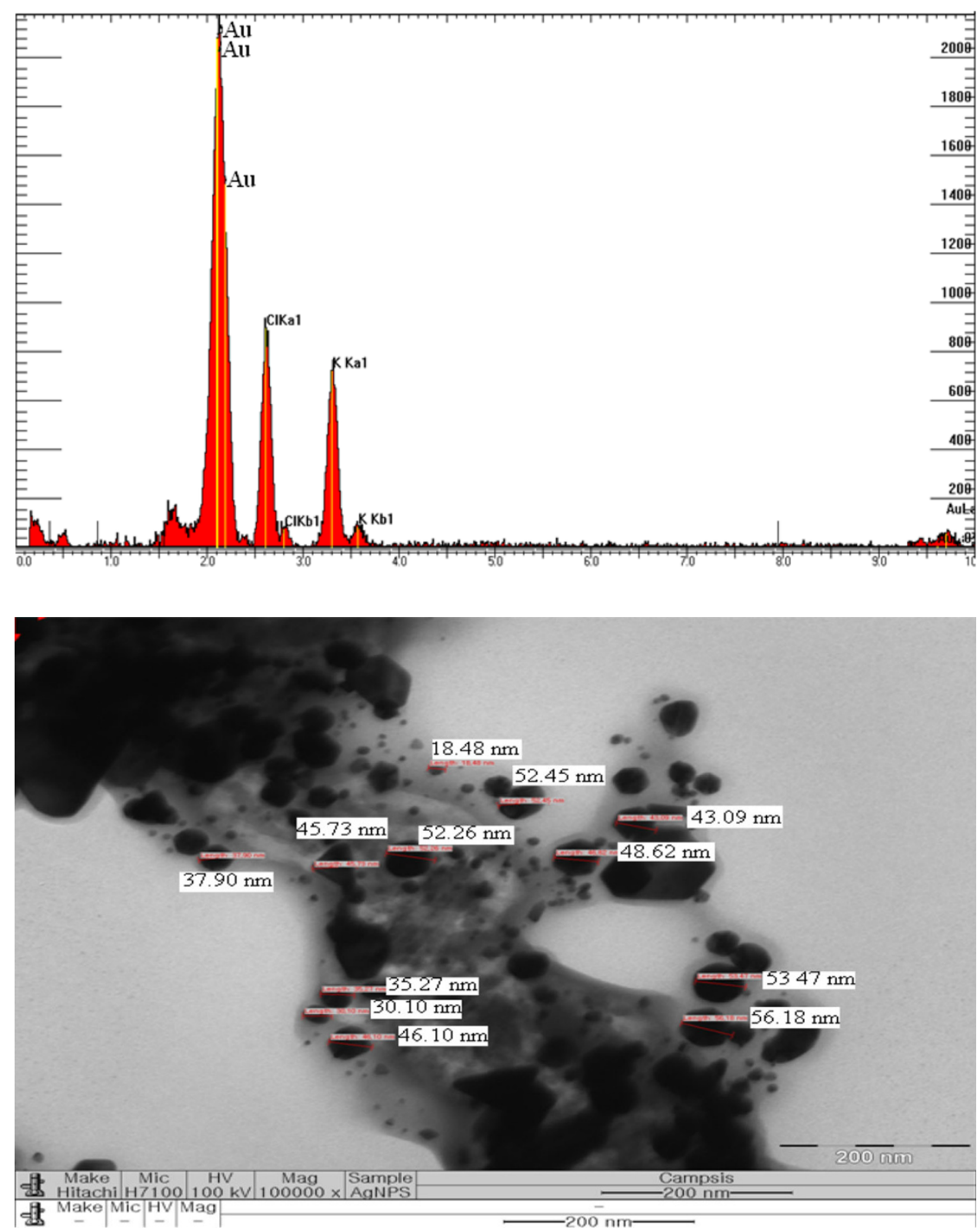

TENSOR 37). Particle sizing experiments were carried out by means of laser diffractometry, using Zeta sizer nano series (Malvern). Measurements were taken in the range of 0.1 and $1 \times 10^{8} \mu \mathrm{m}$.

\section{Bacterial growth curve}

The antibacterial activity of gold nanoparticles against gram-positive and gram-negative bacteria was analyzed by their growth curve. To examine the effect of various concentrations (1, 0.5. 0.25 and $0.125 \mathrm{mM}$ ) of AuNPs on bacteria growth, organisms were grown overnight in nutrient broth $(\mathrm{NB})$ at $37{ }^{\circ} \mathrm{C}$. The growth of gram-positive and gram-negative in broth media was indexed by measuring the optical density (at $\lambda=600 \mathrm{~nm}$ ) using ELISA. Ampicillin used as control.

MTT (dimethyl thiazolyl diphenyl tetrazolium salt) assay

This assay is based on the ability of mitochondria succinate dehydrogenase enzymes in living cells to reduce the yellow water soluble substrate dimethyl thiazolyl diphenyl tetrazolium (MTT) into a purple formazan product which is analyzed spectrophotometer. B16/F10 melanoma cell line was used to examine the toxicity of the present green 
Fig. 6 a-d Transmission electron microscopic micrographs showing anisotropic structures of AuNPs synthesized using the rhizome extract of Dioscorea batatas
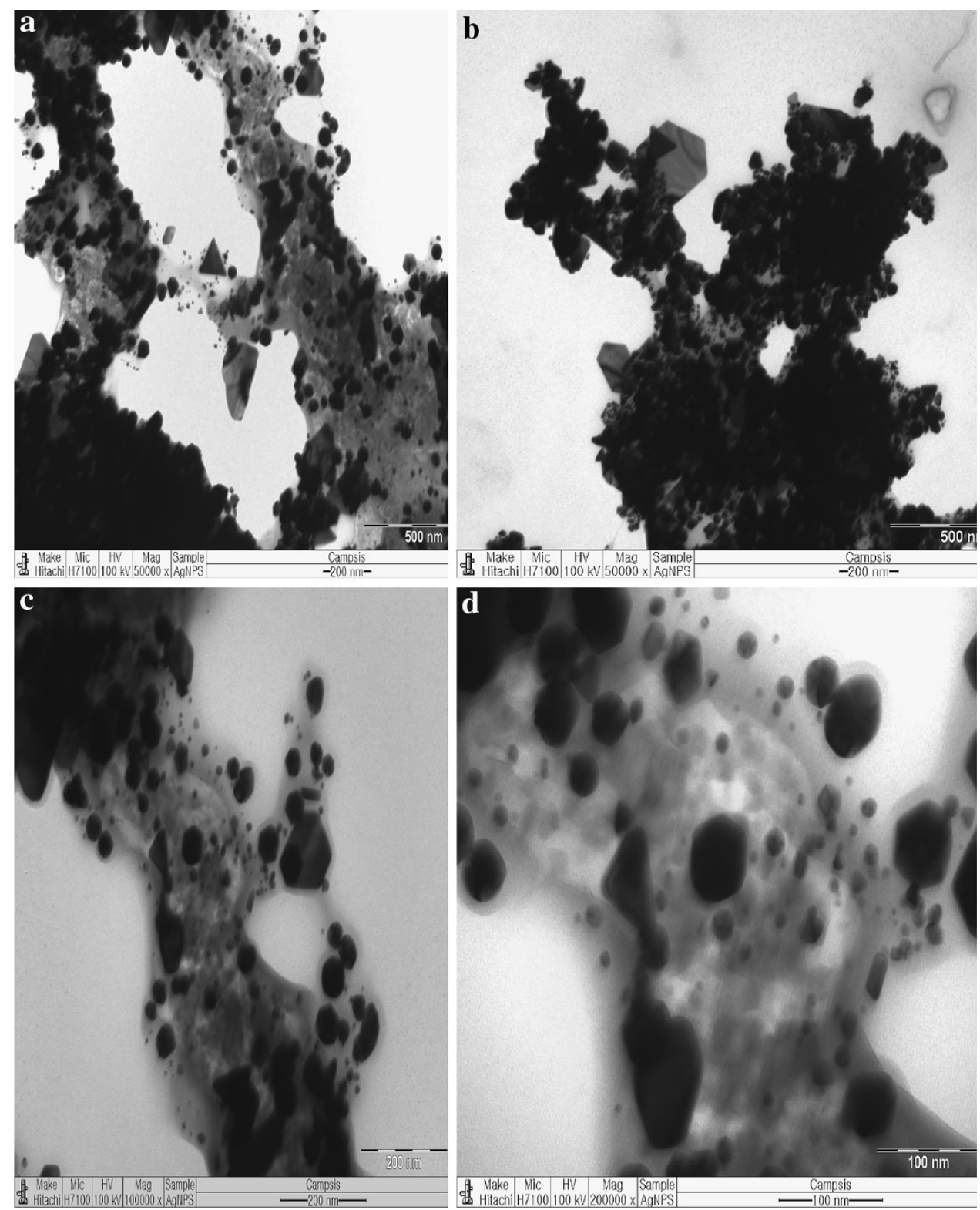

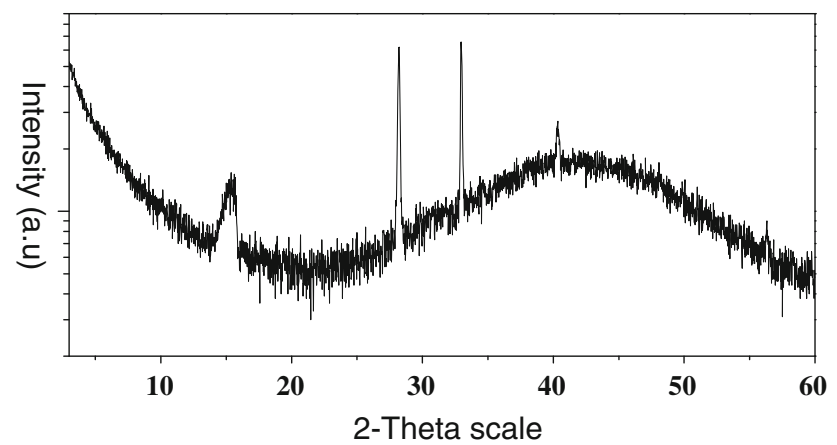

Fig. 7 XRD micrograph showing Bragg's reflections corresponds to the face-centered cubic (FCC) structure of AuNPs synthesized using the rhizome extract of Dioscorea batatas synthesized AuNPs. Cells were sub cultured in DMEM supplemented with $10 \%$ FBS and $1 \%$ penicillin-streptomycin at $5 \% \mathrm{CO}_{2}$ at $37{ }^{\circ} \mathrm{C}$. At about $90 \%$ confluence, cells were harvested using $0.25 \%$ trypsin and were seeded in 24-well plates. To each well, $500 \mu \mathrm{l}$ of diluted cell suspension $\left(3.05 \times 10^{5} \mathrm{cell} / \mathrm{ml}\right)$ was added. After $24 \mathrm{~h}$, when the monolayer formed the supernatant was flicked off and $200 \mu \mathrm{l}$ of different test samples $(1.0,0.8,0.6,0.4$ and $0.2 \mathrm{mM}$ ) were added to the cells, followed by incubation for $48 \mathrm{~h}$. The medium was removed by suction and $200 \mu \mathrm{l}$ of MTT was added to each well. The plates were gently shaken and incubated for $4 \mathrm{~h}$. The supernatant was removed, $200 \mu \mathrm{l}$ of DMSO was added, and the plates were 

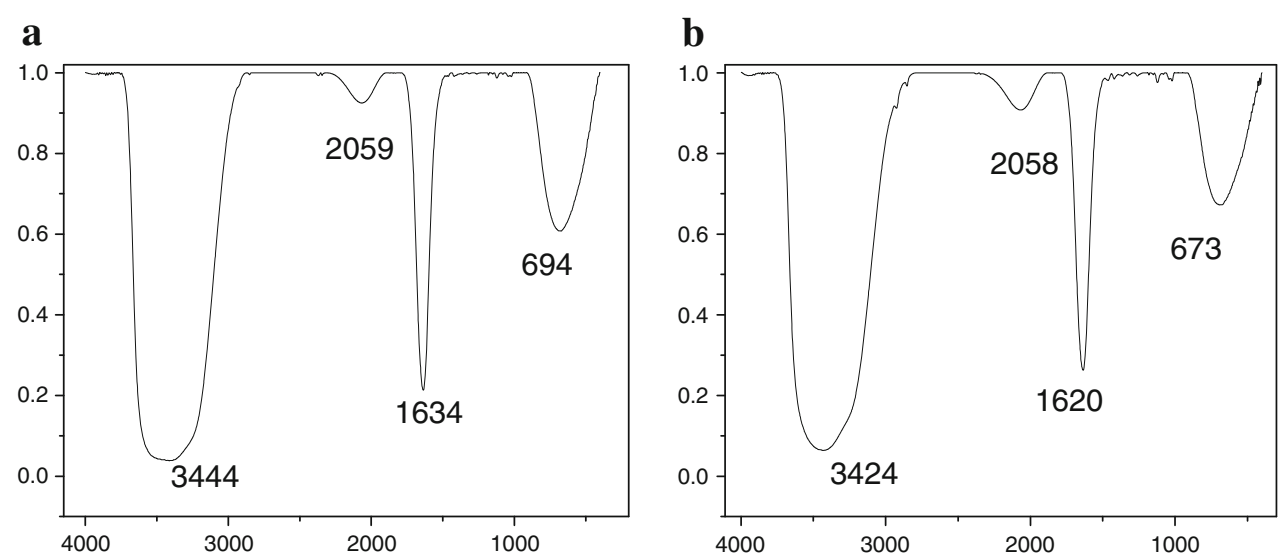

Fig. 8 FT-IR spectrum of a Dioscorea batatas rhizome extract and $\mathbf{b}$ the functional groups responsible for the reduction and stabilization of AuNPs

gently shaken to solubilize the formed formazan. The absorbance was measured using a microplate reader at a wavelength of $570 \mathrm{~nm}$. The experiment was done twice and averaged.

Statistical analysis

Each experiment was maintained with three replications and the data were analyzed using two ways ANOVA.

\section{Results and discussion}

UV-Vis Spectrophotometric studies: Recording of localized surface plasmon resonance (LSPR)

Bioreduction of aqueous $\mathrm{AuCl}_{4}{ }^{-}$ions can easily be followed by UV-Vis spectrophotometer, and one of the most important features in optical absorbance spectra of metal nanoparticles is surface plasmon band, which is due to collective electron oscillation around the surface mode of the particles. Previous studies have shown that gold exhibits red wine color and silver exhibits yellowish-brown color due to the excitations of their surface plasmon response (SPR) (Mulvaney 1996), when dissolved in water. The change in color of the solution was observed (from colorless to dark red wine color) after keeping the solution at $50{ }^{\circ} \mathrm{C}$ for $25 \mathrm{~min}$ (Fig. 2).

In the case of gold, the reduction started within 5 min after the addition and completed in $30 \mathrm{~min}$. The possible explanation of difference in the reduction time could be due to the difference in their reduction potential for both the metal ions. Metal nanoparticles such as gold have free electrons, which give rise to SPR absorption band (Noginov et al. 2007) at and around $555 \mathrm{~nm}$ (Fig. 3). The reduction and stabilization of $\mathrm{Au}^{+}$ions could be done by combinations of biomolecules found in the extracts such as proteins, aminoacids, polysaccharides and vitamins which are evidenced in FT-IR studies (Thirumurugan et al. 2010).

Transmission electron microscopy (TEM) and energy dispersion spectroscopic (EDS) measurements

The EDS spectrum of AuNPs synthesized at $50{ }^{\circ} \mathrm{C}$ is shown in Fig. 4. Strong signals from the gold atoms in the nanoparticles were observed, and signals from $\mathrm{Si}, \mathrm{K}$ and $\mathrm{C}$ atoms were also recorded. The presence of $\mathrm{C}$ and $\mathrm{K}$, signals were likely due to X-ray emission from carbohydrates/ proteins/enzymes present in the cell wall of the biomass. The presence of the elemental gold can be observed in the graph obtained from EDS analysis, which also supports the XRD results. The TEM images of AuNPs are shown in (Figs. 5, 6). The TEM images have shown that the formed AuNPs were polydispersed and were predominately spherical in nature. But it is evident from TEM micrographs that triangular, hexagonal, rod and irregular shaped nanoparticles were also formed.

$\mathrm{X}$-Ray diffraction (XRD): study of crystalline structure of gold nanoparticles

The XRD pattern of the AuNPs is shown in (Fig. 7). Bragg reflections obtained in the micrograph clearly indicated the presence of (111) and (200) sets of lattice planes which is a consequence of crystalline nature of formed AuNPs and indexed as face-centered-cubic (FCC) structure of gold. In addition to the Bragg peaks representative of FCC AuNPs, additional as yet unassigned peaks are also observed suggesting that the crystallization of bio-organic phase occurs on the surface of the nanoparticles. 
Fig. 9 Particle size distribution of AuNPs by size, volume and correlation synthesized using Dioscorea batatas rhizome extract
Size Distribution by Intensity

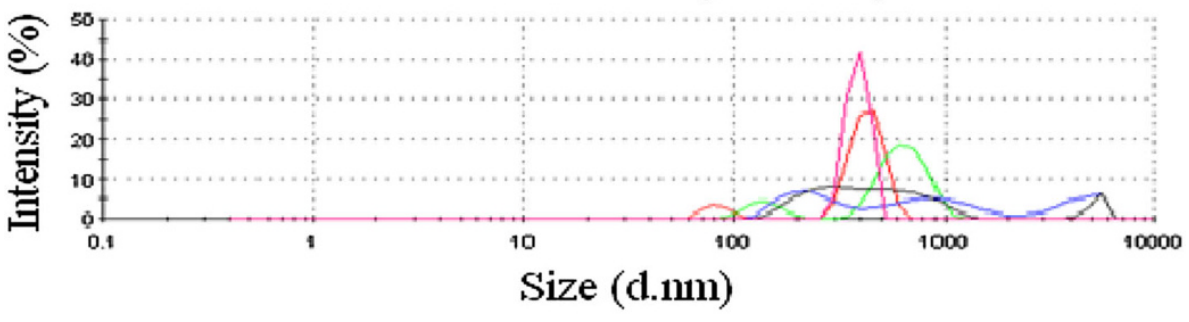

Size Distribution by volume

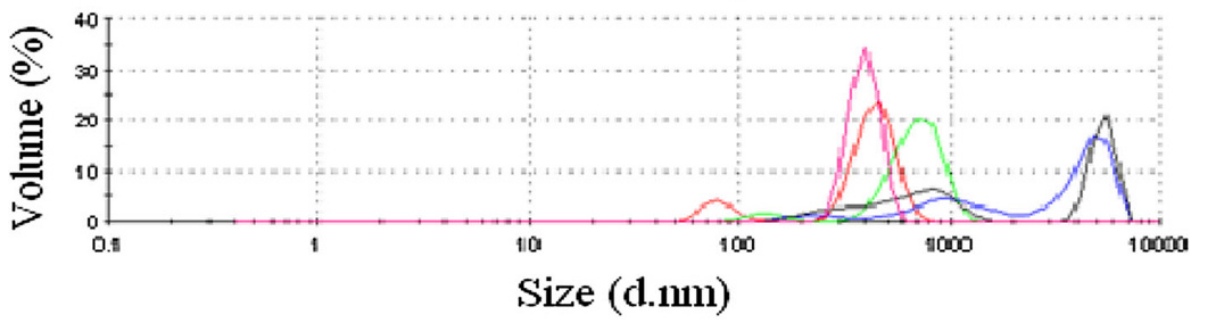

Raw Correlation Data

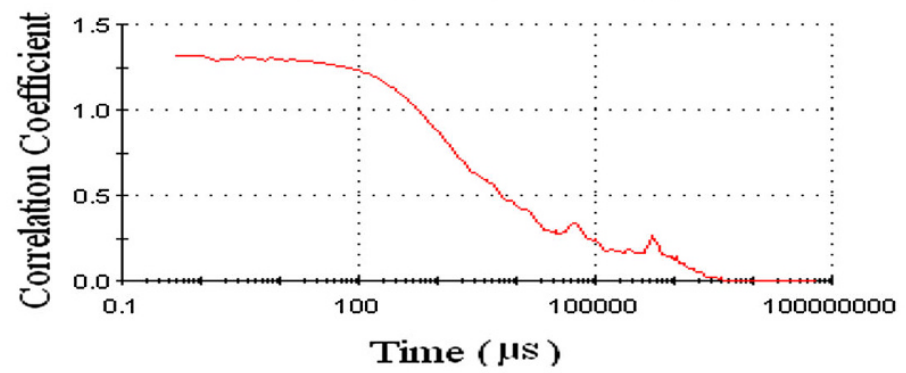

Size Distribution by Intensity

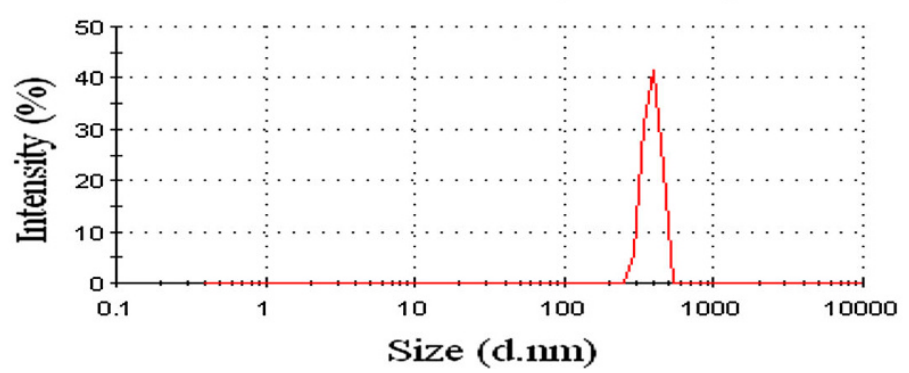

attributed to the stretching vibration of $-\mathrm{C}=\mathrm{C}$ (alkane) ( $\mathrm{Zhu}$ 2000). Amines are a particularly attractive class of reducing agents because of their structural or chemical properties (Newman and Blanchard 2006). Thus, the FT-IR micrograph reveals that amides that are present in the extract are responsible for the reduction and stabilization of the gold nanoparticles.

Dynamic light scattering (DLS) technique: particle size measurement of hydrosol

Particle size determination of the formulated AuNPs was shown under different categories like size distribution by 
Fig. 10 Growth curves of, Staphylococcus aureus (KCTC 1916), Staphylococcus epidermidis (KCTC 1917) and Escherichia coli (KCTC 2441) in the presence of different AuNPs concentrations

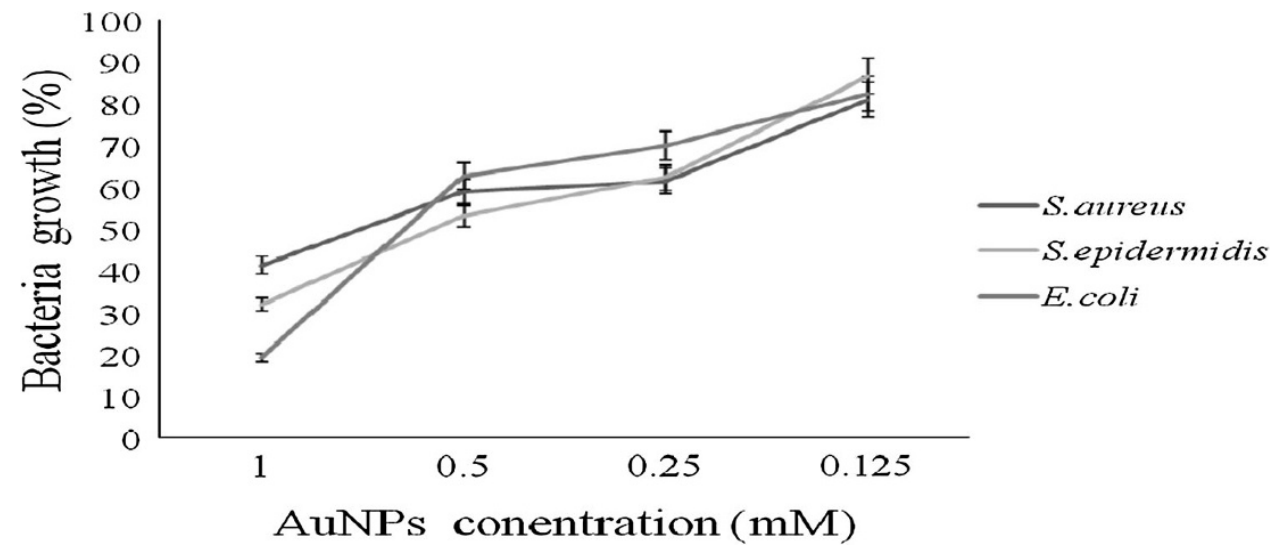

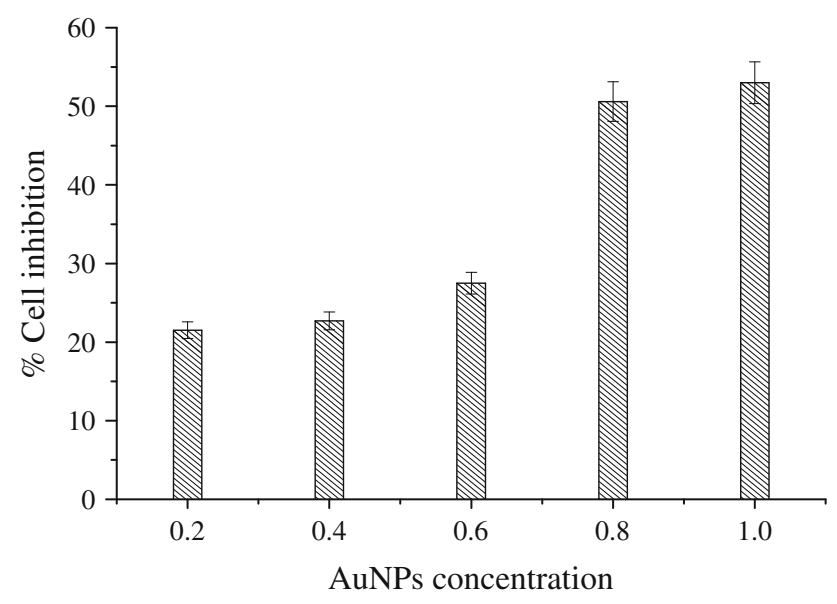

Fig. 11 Cytotoxic effect of AuNPs synthesized using Dioscorea batatas rhizome extract on B16/F10 melanoma cells cell line by MTT (dimethyl thiazolyl diphenyl tetrazolium salt) assay

volume and intensity (Fig. 9). The size distribution by volume gives a bell shaped (Fig. 9) pattern which indicates the wide range size distribution of nanoparticles in the sample formulation. The volume $\%$ of the samples were found to be in the range of $0.1-1 \times 10^{8}$ (AuNPs) The formed AuNPs are well distributed with respect to volume and intensity, an indication of the formation of well built AuNPs and their mono and poly disparity, respectively.

Antibacterial and cytotoxicity activities of AuNPs

The growth curves of $S$. aureus $(41.1,58.8,61.3$ and $80.77 \%)$ S. epidermidis $(31.8,52.88,62.14$ and $86.5 \%)$ and E. coli $(19.1,62.43,69.84$ and $82.2 \%)$ in MH broth medium in the presence of AuNPs at 1, 0.5, 0.25 and $0.125 \mathrm{mM}$ concentrations are shown in Fig. 10. Zhang et al. (2008) used an amido-amine coated AuNPs and tested their toxicity on a large suite of gram-negative and positive bacteria. At $2.8 \mathrm{mg} / \mathrm{L}$, AuNPs demonstrated up to a $98 \%$ inhibition of bacterial growth. Gold nanoparticles possess well-developed surface chemistry, chemical stability and appropriate smaller size, which make them easier to interact with the microorganisms (Nirmala Grace et al. 2007). Also, the particles interact with the building elements of the outer membrane and might cause structural changes, degradation and finally cell death (Zawrah and Sherein 2011).

The incubation of B16/F10 melanoma cells with synthesized AuNPs significantly reduced the viability of these cells in a dose dependent manner and all concentrations $(0.2-1 \mathrm{mM})$ were found toxic to the cells (Fig. 11). The maximum inhibition of proliferation was $52.98 \%$ at higher concentration $(1 \mathrm{mM}) ; 21.51 \%$ minimum cell inhibition observed at lower concentration $(0.2 \mathrm{mM})$. From the results, it is evident that synthesized AuNPs have inhibitory effect on SGT oral cancer cells. It is also important to recognize that a vast majority of gold (I) and gold (III) compounds show varying degrees of cytotoxicity to a variety of cells (Basset et al. 2003). Further size and shape dependent uptake of gold nanoparticles into mammalian cells has been reported and points to the need of in depth study of size and shape dependent antimicrobial and cytotoxic effects of nanoparticles (Devika Chitrani et al. 2006).

\section{Conclusion}

The rhizome extract of Dioscorea batatas is found to be one of the potential candidates for the green synthesis of AuNPs. The spectroscopic characterization data such as UV-Vis, FT-IR and SEM also support the formation and stability of the bio-synthesized AuNPs. Low bacteria growth observed in $1 \mathrm{mM}$ concentration. $21.51 \%$ cell inhibition observed at lower concentration $(0.2 \mathrm{mM})$ and maximum cell inhibition $(52.98 \%)$ was observed at higher concentration $(1 \mathrm{mM})$. This simple, efficient and rapid green synthesis of AuNPs can be used to produce large scale production of gold nanoparticles for their use in various biomedical and biotechnological applications.

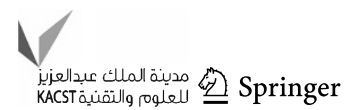


Open Access This article is distributed under the terms of the Creative Commons Attribution License which permits any use, distribution, and reproduction in any medium, provided the original author(s) and the source are credited.

\section{References}

Arunachalam KD, Annamalai SK, Hari S (2013) One-step green synthesis and characterization of leaf extract-mediated biocompatible silver and gold nanoparticles from Memecylon umbellatum. Int J Nanomed 8:1307

Aswathy Aromal S, Philip D (2012) Spectroch. Acta. A: green synthesis of gold nanoparticles using Trigonella foenum-graecum and its size-dependent catalytic activity. Mol Biomol Spectrosc 97:1

Au ALH, Kwok CC, Lee ATC, Kwan YW (2004) Acute simvastatin inhibits $\mathrm{K}_{\mathrm{ATP}}$ channels of porcine coronary artery myocytes. Eur J Pharmacol 502:123

Bar H, Bhui DK, Sahoo GP, Sarkar P, Pyne S, Misra A (2009) Synthesis of silver nanoparticles using latex of Jatropha curcas. Colloid Surf A: Physicochem Eng Aspects 348:212

Basset C, Vadrot J, Denis J, Poupon J, Zafrani ES (2003) Prolonged cholestasis and ductopenia following gold salt therapy. Liver Int 23:89

Choi EM, Hwang JK (2002) Enhancement of oxidative response and cytokine production by yam mucopolysaccharide in murine peritoneal macrophage. Fitoterapia 73:629

Choi EM, Koo SJ, Hwang JK (2003) Synergistic induction of iNOS by IFN- $\gamma$ and glycoprotein isolated from Dioscorea batatas. J Ethnopharmacol 91:1

Devika Chitrani B, Ghazani AA, Chan WCW (2006) Determining the Size and shape dependence of gold nanoparticle uptake into mammalian cells. Nanoletters 6:662

Li-Na M, Dian-Jun L, Zhen-Xin W (2011) Nanomaterials for medical application. Chin J Anal Chem 38:1

Mayer AMS, Rodriguez AD, Berlinck RGC, Fusetani N (2011) Marine compounds with antibacterial, antidiabetic, antifungal, anti-inflammatory, antiprotozoal, antituberculosis, and antiviral activities; affecting the immune and nervous systems, and other miscellaneous mechanisms of action. Comp Biochem Physiol C: Toxicol Pharmacol 153:191-222

Morrison EY, Ragoobirsingh D, Peter SA (2006) The unitarian hypothesis for the aetiology of diabetes mellitus. Med Hypotheses 67:1115

Mulvaney P (1996) Surface plasmon spectroscopy of nanosized metal particles. Langmuir 12:788

Nagajyothi PC, Sreekanth TVM, Prasad TNVKV, Lee KD (2012a) Green synthesis of silver and gold nanoparticles using Lonicera Japonica flower extract. Adv Sci Lett 5:124

Nagajyothi PC, Lee SE, An Minh, Lee KD (2012b) Green Synthesis of silver and gold nanoparticles using Lonicera Japonica flower extract. Bull Korean Chem Soc 33:2609

Nagajyothi PC, Lee KD, Sreekanth TVM (2013) Plants as green source towards synthesis of nanoparticles. J Optoelectron Adv Mater 15:269
Newman JDS, Blanchard GJ (2006) Formation of gold nanoparticles using amine reducing agents. Langmuir 22:5882

Nirmala Grace A, Pandian K, Collo. Surfa A (2007) Antibacterial efficacy of aminoglycosidic antibiotics protected gold nanoparticles-a brief study. Physicochem Eng Aspects 297:63

Noginov MA, Zhu G, Bahoura M, Adegoke J, Small C, Ritzo BA, Drachev VP, Shalaev VM (2007) The effect of gain and absorption on surface plasmons in metal nanoparticles. Appl Phys B 86:455

Phillip D (2010) Spectroch. Acta. A: Gnidia glauca flower extract mediated synthesis of gold nanoparticles and evaluation of its chemocatalytic potential. Mol Biomol Spectrosc 77:807

Prasad TNVKV, Giridhara Krishna T (2012) Soil nanoscience: plenty of room at the bottom. World J Appl Environ Chem 1:72-75

Rajasekharreddy P, Usha Rani P, Sreedhar B (2011) Green synthesis of silver-protein (core-shell) nanoparticles using Piper betle L. leaf extract and its ecotoxicological studies on Daphnia magna. J Colloids Surf A: Physiochem Eng Aspects 12:1711

Ramgopal M, Saisushma C, Attitalla IH, Alhasin AM (2011) A facile green synthesis of silver nanoparticles using soap nuts. Res J Microbiol 6:432

Sharma VK, Yngard RA, Lin Y (2009) Silver nanoparticles: green synthesis and their antimicrobial activities. Adv Colloid Interface Sci 145:83

Singaravelu G, Arockiamary JS, Ganesh Kumar V, Govindaraju K (2007) A novel extracellular synthesis of monodisperse gold nanoparticles using marine alga, Sargassum wightii Greville. Colloid Surf B-Biointerface 57:97

Sunil P, Goldie O, Mewada A, Sharon M (2012) Green synthesis of highly stable gold nanoparticles using Momordica charantia as nano fabricato. Arch Appl Sci Res 4:1135

Tetty CO, Nagajyothi PC, Lee SE, Ocloo A, Minh An TN, Sreekanth TVM, Lee KD (2012) Anti-melanoma, tyrosinase inhibitory and anti-microbial activities of gold nanoparticles synthesized from aqueous leaf extracts of Teraxacum officinale. Int J Cosmet Sci $34: 150$

Thirumurugan A, Jiflin GJ, Rajagomathi G, Neethu Anns T, Ramachandran S, Jaiganesh R (2010) Synthesis of gold nanoparticles of Azadirachta indica leaf extract. Int J Biol Technol $1: 75$

Tikariha S, Singh S, Banerjee S, Vidyarthi AS (2012) Anthelmintic efficacy of gold nanoparticles derived from a phytopathogenic fungus Nigrospora oryzae. Int J Pharma Sci Res 3:1603

Zawrah MF, Sherein I (2011) Antimicrobial activities of gold nanoparticles against major foodborne pathogens. Life Sci J 8:37

Zhanh Y, Peng H, Huang W, Zhou Y, Yan DJ (2008) Facile preparation and characterization of highly antimicrobial colloid $\mathrm{Ag}$ or Au nanoparticles. Colloid Interface Sci 325:371

Zhu M (2000) Biocompactibility synthesis of silver and gold nanoparticles. Apparatus analyses. Higher education press, Beijing 